\title{
BMJ Open Suicide and self-harm trends in recent immigrant youth in Ontario, 1996-2012: a population-based longitudinal cohort study
}

\author{
Natasha Ruth Saunders, ${ }^{1,2,3,4}$ Michael Lebenbaum, ${ }^{3}$ Therese A Stukel, ${ }^{3,5,6}$ \\ Hong Lu, ${ }^{3}$ Marcelo L Urquia, ${ }^{3,5,6,7,8}$ Paul Kurdyak, ${ }^{3,5,6,9}$ Astrid Guttmann ${ }^{1,2,3,4,5,6}$
}

To cite: Saunders NR, Lebenbaum M, Stukel TA, et al. Suicide and self-harm trends in recent immigrant youth in Ontario, 1996-2012: a population-based longitudinal cohort study. BMJ Open 2017;7:e014863. doi:10.1136/ bmjopen-2016-014863

\section{- Prepublication history for} this paper is available online. To view these files please visit the journal online (http://dx.doi org/10.1136/bmjopen-2016014863).

Received 29 0ctober 2016 Revised 23 May 2017 Accepted 24 May 2017

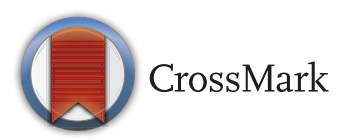

For numbered affiliations see end of article.

Correspondence to Dr Natasha Ruth Saunders; natasha.saunders@sickkids.ca

\section{ABSTRACT}

Objective To describe the trends in suicide and emergency department (ED) visits for self-harm in youth by immigration status and immigrant characteristics.

Design Population-based longitudinal cohort study from 1996 to 2012 using linked health and administrative datasets. Setting Ontario, Canada.

Participants Youth 10 to 24 years, living in Ontario, Canada.

Exposure The main exposure was immigrant status (recent immigrant (RI) versus long-term residents (LTR)). Secondary exposures included region of birth, duration or residence, and refugee status.

Main outcome measure Trends over time in suicide and ED self-harm were modelled within consecutive 3-year time periods. Rate ratios were estimated using Poisson regression models.

Results 2.5 to 2.9 million individuals were included per cohort period. LTR suicide rates ranged from 7.4 to 9.4/100000 male person-years versus 2.2-3.4/100000 females. Rl's suicide rates were $2.7-7.2 / 100,000$ male versus 1.9-2.7/100000 female person-years. Suicide rates were lower among RI compared with LTR (adjusted relative rate $(\mathrm{aRR})=0.70,95 \% \mathrm{Cl}=0.57$ to 0.85 ) with different mechanisms of suicide. No significant time trend in suicide rates was observed $(p=0.40)$. ED self-harm rates for LTR and RI were highest in females (2.6-3.4/1000 LTR females versus $1.1-1.5 / 1000$ males, $1.2-1.8 / 1000 \mathrm{RI}$ females versus $0.4-0.6 / 1000$ males). $\mathrm{Rl}$ had lower rates of selfharm compared with $\mathrm{LTR}(\mathrm{aRR}=0.60,95 \% \mathrm{Cl}=0.56$ to 0.65$)$. Stratum-specific rates showed a steeper decline per period in RI compared with LTR (RI: $\mathrm{aRR}=0.85,95 \% \mathrm{Cl}=0.81$ to 0.89 ; LTR: $\mathrm{aRR}=0.91,95 \% \mathrm{Cl}=0.90$ to 0.93 ). Observed trends were not universal across region of origin and by refugee status. Interpretation Suicide rates have been stable and ED self-harm rates are declining over time among $\mathrm{Rl}$ youth. These trends by important subgroups should continue to be monitored to allow for early identification of subpopulations of immigrant youth in need of targeted and culturally appropriate public health interventions.

\section{INTRODUCTION}

Suicide is a leading cause of death among youth in upper-middle and high-income countries, second only to death from motor
Strengths and limitations of this study

- Strengths of this study are that it is the first population-based study to evaluate trends over time in suicide and self-harm in immigrant youth. In particular, we were able to include detailed immigration data including immigration class and duration of residence were included for a large population with objective measures of mental health problems that were not based on self-report.

- Limitations include no measures of clinical comorbidities or language proficiency and our inability to extend findings to temporary and nonstatus immigrants,

- The rarity of suicide did not allow for study of trends in subpopulations of recent immigrant subgroups.

vehicle collisions. ${ }^{1}$ Similarly, non-fatal self-inflicted injuries are a common cause of visits to the emergency department. ${ }^{2}$ Despite growing global interest in the epidemiology of mental health in children and youth, little is known about suicide and self-harm risk within subpopulations of youth, including immigrants, and how this risk has changed over time. Evidence from the United States of America suggests that there are emerging racial $^{3}$ and urban-rural ${ }^{4}$ disparities in youth suicide over the last two decades. Accordingly, without stratifying by sociodemographic characteristics such as immigration status, important trends in risk factors, either protective or precipitating, may be obscured. Finding targeted interventions for specific at-risk groups for mental health problems has been proposed as one way of identifying more successful treatments than currently available. $^{5}$

While suicide and self-harm behaviours among youth are universal, worldwide rates vary considerably. For example, across all ages, most Middle Eastern countries have 
rates of less than two suicides per 100000 population per year, whereas in Guyana, rates are as high as 44 suicides per 100000 population per year and global rates average approximately 16 suicides per 100000 population per year. ${ }^{6}$ In Ontario, Canada's most populous province where $50 \%$ of immigrants to Canada settle, and across all of Canada, the suicide rates are approximately 8 and 10 per 100000 population per year, respectively. ${ }^{6}$ With migration to another country, adult immigrants bring the risk of suicide of their country of origin with them to their new country, ${ }^{89}$ though this has not been studied in youth. Moreover, with migration youth face a number of immigration-related stressors-changes in social, cultural and economic environments-that may impact on their well-being and risk for self-harm and suicide. As migration continues to be an increasing global phenomenon, understanding risk factors for poor mental health with migration is important.

At $20.6 \%$ of the total population, Canada has the second largest and most diverse immigrant population in the world..$^{10}$ A defining feature of Canadians is the heterogeneity of their ancestry, making Canada an ideal setting to measure trends in health outcomes in immigrant populations. Healthcare in Canada, funded through provincially regulated ministries, ensures universal insurance coverage for most physician and hospital services at no personal cost for residents including recent immigrants who have obtained permanent residency status. Over the past two decades, like most receiving countries around the world, the composition of immigrants to Canada has changed. Whereas in the mid-1990s to late 1990s, most immigrants were from Europe and Central Asia, now, over half originate from South and East Asia. ${ }^{11}$ In-country suicide rates in the former region (eg, France, United Kingdom) are typically more similar to Canada whereas those from South Asia (eg, India, Sri Lanka) are higher and those from East Asia (eg, China, Philippines) are typically lower than Canadian rates. ${ }^{6}$ These shifts in migration patterns may have altered the rates of suicide and self-harm behaviours within Canada as circumstances surrounding reasons for migration, country-level conditions and receiving country factors, including access to care and reduced mental health stigma over time, may have also changed. In Canada, youth suicide trends have been stable over time, but subgroup analyses by sex demonstrate that female suicides have been increasing while male suicides have been declining. ${ }^{12}$ In contrast, non-fatal suicide-related behaviours have declined by $30 \%$ throughout the past decade in both sexes in Canada. ${ }^{13}$ The role immigration has played in the observed trends in mental health among youth is not known. Understanding these changes is critical to optimal health service delivery and targeted health service improvements to reduce suicide and self-harm behaviours.

The objectives of this study were to describe the trends in the rates of suicide and ED visits for self-harm in recent immigrant youth compared with long-term residents of Canada. Additionally, we aimed to describe these trends and rates among subgroups of immigrants, including by immigrant class (refugees and non-refugees), duration of residence in Canada, and by region of birth. Given Ontario's universal access to healthcare for immigrants, selection policies that bring highly skilled and educated immigrants to Canada, and the individual motivation level of those who are able to immigrate to Canada, we hypothesised that overall rates of suicide and self-harm would be lowest among recent immigrants, including refugees compared with long-term residents. We also hypothesised that rates of both outcomes would decline over time because of improved awareness of mental health challenges immigrants face, reduced stigma, and increased community and social supports that help immigrants integrate and settle in Canada.

\section{METHODS \\ Study design}

This was a population-based, longitudinal cohort study of suicide and ED self-harm among youth between 10 and 24years of age, living in Ontario between 1996 and 2012, identified through records from the Ontario Registered Persons Database (RPDB), Ontario's health system registry. Under the Ontario Health Insurance Plan (OHIP), universal coverage for most physician and hospital services are provided to every legal resident, including recent immigrants, and tracked through an Ontario health card number, which is encoded. Records from multiple health and administrative databases were linked using unique, encoded identifiers at the Institute for Clinical Evaluative Sciences (ICES) in Toronto, Canada. Research ethics approval was obtained from the Sunnybrook Health Sciences Centre Research Ethics Board.

\section{Data sources}

Immigration, Refugees and Citizenship Canada's (IRCC) Permanent Resident Database was used to obtain immigration information. This database contains individual level data from permanent residents who have immigrated to Canada and landed in Ontario from 1985 to 2012 and includes their visa class, country of birth and year of landing. Data from asylum-seekers (those arriving in Canada and subsequently seeking refugee status) are not available through this database, nor are health records from non-status immigrants. Overall probabilistic linkage to the RPDB identifies approximately $86 \%$ of immigrants. ${ }^{14}$ ED visits were ascertained from the National Ambulatory Care Reporting System (NACRS) (available 2002 to 2012). To determine the number of suicides, the Ontario Registrar General Vital Statistics-Deaths (ORGD) was used (available from 1996 to 2012). Neighbourhood income quintile and community size were derived by linking Statistics Canada's Postal Code Conversion File to the patient's postal code. 


\section{Study population}

Children and youth living in Ontario and eligible for OHIP between 1996 and 2012 were included. Observation windows were grouped into 3-year periods (2-year for the final period) to allow for analyses of rare outcomes with computational ease. Children and youth entered and exited the study on their 10th and 25th birthdays, respectively. Those with an invalid health card number and missing sex were excluded. To prevent unlinked IRCC records from being misclassified as Canadian born and to exclude immigrants who moved to Ontario from another province, those without an IRCC record who first became eligible for OHIP during the observation period or within 5 years prior to each cohort period were excluded.

\section{Exposure variables}

Immigrant status was the main exposure. Recent immigrantss included those with an IRCC Permanent Resident Database record and duration of residence in Ontario $<10$ years. The remainder of the population, long-term residents, included all Canadian born Ontario residents and individuals with an IRCC Permanent Resident Database record who had landed in Canada $\geq 10$ years from the start of the cohort period. Immigrant status was determined at the beginning of each period. Provided that individuals maintained OHIP eligibility and study age criteria, recent immigrants in one period could become long-term residents in an ensuing period.

Recent immigrantss were subsequently grouped by refugee status (a status determined by IRCC based on the immigration class to which they apply), duration of residence in Ontario ( $<5$ years and $\geq 5$ years) and region of birth based on modified World Bank Regions. ${ }^{15}$ Age, sex, neighbourhood income quintile within a dissemination area, and community size based on the 2006 Canadian Census were also included as covariates. All covariates were measured at the beginning of the 3-year period.

\section{Outcome measures}

The primary outcome measures were suicide and ED selfharm visits within each time period. Suicide was measured from the Ontario Registrar General - Vital Statistics Database where the cause of death was either due to suicide or self-harm. ED self-harm visits were identified in NACRS where any of the diagnoses were for intentional self-harm (International Classification of Disease (ICD), 9th edition diagnosis code E950-E959 or 10th edition diagnosis code $\mathrm{X} 60-\mathrm{X} 84$ ). Visits were then characterised by the mechanism of suicide or ED self-harm based on their ICD 9th or 10th edition diagnosis code.

\section{Statistical analysis}

For each time period, the total number of individuals, person-years of exposure and the number and rate of suicide and ED self-harm events were used to compute event rates. For the models, the unit of analysis was the individual resident. Multivariable Poisson models were used to assess the relationship between suicide and self-harm rates and immigrant status, adjusting for age, sex, income quintile and community size. Generalised estimating equations (GEE) were used to account for the correlations among an individual's event rates over time periods using an independence correlation structure. As clustering may cause variance overdispersion, using GEE permitted estimation of this overdispersion. The interaction between immigrant status and time was tested and where significant, separate time trends were estimated for each immigrant group. Adjusted time trends for recent immigrant subgroups (region of birth and duration of residence and refugee status) were also estimated. All analyses were conducted with SAS Enterprise Guide, version 6.1 .

ICES allows usage of health administrative data without individual consent for health system research, provided strict privacy guidelines are met. Institutional policy requires suppression of cell sizes $<6$ to ensure non-identification. To meet privacy requirements, small cell sizes were suppressed.

\section{RESULTS}

Each 3-year time period included approximately 2.5 to 2.9 million individuals. Long-term residents comprised $88.5 \%$ to $90.2 \%$ of each cohort. Among recent immigrants, $17.7 \%$ to $18.0 \%$ were refugees. In the earlier years of the study, most immigrants came from Europe and Central Asia, whereas in later years most immigrated from South and East Asia (table 1).

\section{Suicide trends}

Over the study period, there were 1906 and 110 suicides for LTR and recent immigrants, respectively. Suicide rates were highest in male long-term residents (ranging from 7.4 to 9.4 per 100000 ) with female long-term resident rates between 2.2 to 3.4 per 100000 (figure 1). Male recent immigrants had suicide rates of 2.7 to 7.2 per 100000 person-years and female recent immigrant suicide rates were 1.9 to 2.7 per 100000 person-years (figure 1). Regression analyses assessing the association between immigration status and suicide rates showed a $30 \%$ lower rate among recent immigrants compared with long-term residents (adjusted relative rate $(\mathrm{aRR})=0.70$, $95 \% \mathrm{CI}=0.57$ to 0.85 ). There were no significant time trends in the rates of suicide over the past two decades.

Predictors of suicide are shown in table 2 with males having an almost threefold greater risk of suicide compared with females. Other predictors of suicide included older age groups (15 to 19 and 20 to 24 years), lowestneighbourhood income quintile, and residence in any community size smaller than 1.5 million people.

Time trend analysis within subgroups of immigrants was not feasible due to low rates of suicide within recent immigrant groups. Pooled analysis showed no significant difference in suicide rates in recent immigrants comparing refugees and non-refugees (table 3). Compared with North America, Europe and Central Asia, 
Table 1 Number of OHIP eligible children and youth by period in Ontario, Canada

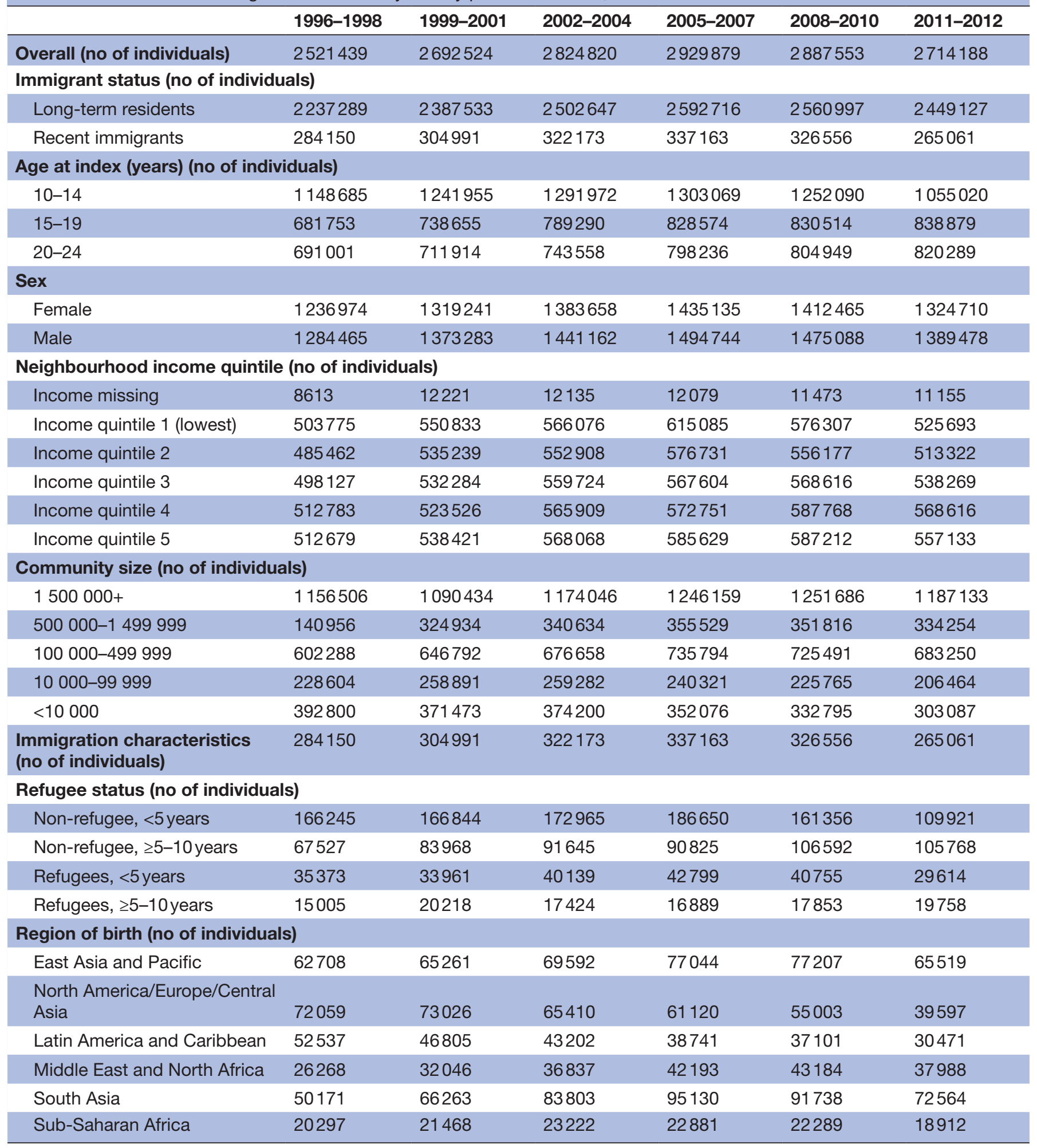

OHIP, Ontario Health Insurance Plan.

only immigrants from Latin America and the Caribbean had lower rates of suicide.

Among long-term residents, the most common mechanism of suicide was hanging with relatively large proportions by firearm and poisoning. Conversely, less than half of recent immigrants completed suicide by hanging and almost one third by jumping from a high location (figure 2).

ED self-harm trends

Long-term residents had 48921 and recent immigrants had 2262 ED self-harm events during the study period. 


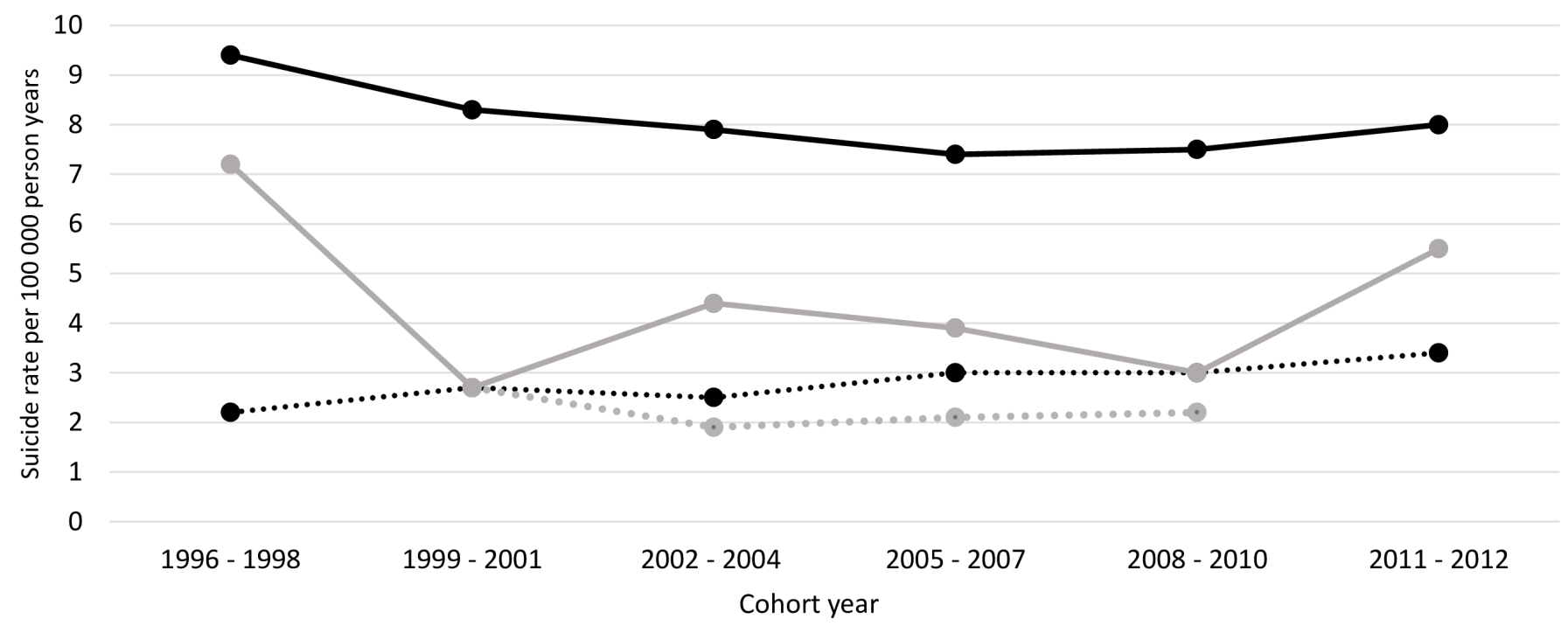

.••.• Female - long-term resident - Male - long-term resident $\cdots \odot$ - Female - recent immigrant - Male - recent immigrant

\footnotetext{
* Suicides in recent immigrant females for 1996-1998 and 2011-2012 <6 therefore rates not reported to prevent re-identification of small cells sizes as per institutional policy.
}

Figure 1 Trends in suicide by immigrant status and sex.

ED self-harm rates for long-term residents were 2.6 to 3.4 per 1000 long-term resident females and 1.1 to 1.5 per 1000 long-term resident males. Among recent immigrants, rates were 1.2 to 1.8 per 1000 for females and 0.4 to 0.6 per 1000 for males (figure 3 ). $18.4 \%$ of LTRs versus $11.5 \%$ of recent immigrants had more than one ED selfharm event. Regression analysis testing the association between ED self-harm and immigration status showed an estimated rate $40 \%$ lower in recent immigrants $(\mathrm{aRR}=0.60,95 \% \mathrm{CI}=0.56$ to 0.65$)$ compared with longterm residents (table 2 ). There was a significant interaction between time and immigration status $(p=0.005)$ and therefore stratum-specific slopes are reported. Both groups showed declining trends in ED self-harm with a faster rate of decline among recent immigrants $(\mathrm{aRR}=0.85,95 \% \mathrm{CI}=0.81$ to 0.89$)$ compared with longterm residents $(\mathrm{aRR}=0.91,95 \% \mathrm{CI}=0.90$ to 0.93$)$. Female sex, late adolescence (15 to 19 years), lower neighbourhood income quintile, and any residence in any community size smaller than 500000 people were associated with increased rates of ED self-harm.

Regression analysis within recent immigrants showed significant decreasing trends in rates of ED self-harm except for immigrant refugees who had been in Canada 5 to 10 years where no change over time was observed (table 4 ). Recent (<5years in Canada) refugees had the highest rates of ED self-harm compared with recent non-refugee immigrants. Coming from a 'non-Western' region was associated with declining rates of ED self-harm (table 4).

The mechanism of self-harm was different between groups with recent immigrants having a higher proportion of self-harm events by poisoning compared with their same-sex long-term resident counterparts $(\mathrm{p}<0.001)$ (figure 2).

\section{DISCUSSION}

In this large, population-based, longitudinal study, we report no significant change over time in suicide rates in recent immigrant and long-term resident youth in Ontario, Canada. Declining rates in ED self-harm were observed in both groups, though at a faster rate among RI. However, within the recent immigrant population, ED self-harm visit rates have not decreased in refugees residing in Canada for 5 to 10 years or in recent immigrants from Europe, the Americas and Central Asia. Recent immigrants had the lowest rates of both suicide and ED self-harm. The methods for suicide and selfharm were different between long-term residents and recent immigrants. Among recent immigrants, refugees had no difference in the rate of suicide compared with non-refugees, though newcomer ( $<5$ years in Canada) refugees had higher rates of ED self-harm compared with newcomer non-refugees.

Most reported trends in suicide including global ones from the World Health Organization, have shown declining rates over the past one to two decades, though considerable inter-country and inter-regional variation exists. ${ }^{6}$ 16-18 While rates in our study population failed to show similar global success in suicide reduction, the frequency of suicide in Canada is relatively low. ${ }^{6}$ Evidence for the value of exploring suicide trends in subpopulations of youth to unmask emerging vulnerable groups is mounting. Recent trend studies have uncovered important differences in rates between males and 
Table 2 Descriptive results and multivariable regression models of emergency department self-harm visits and suicide trends by immigration status

\begin{tabular}{|c|c|c|c|c|c|}
\hline \multicolumn{3}{|c|}{ Emergency department self-harm } & \multicolumn{3}{|c|}{ Suicide } \\
\hline \multirow[b]{2}{*}{ Parameter } & no & $\begin{array}{l}\text { Adjusted relative } \\
\text { rate }\end{array}$ & \multirow[b]{2}{*}{ Parameter } & \multirow[t]{2}{*}{ no } & \multirow{2}{*}{$\begin{array}{l}\text { Adjusted relative } \\
\text { rate } \\
\text { (95\% Cl) }\end{array}$} \\
\hline & & $(95 \% \mathrm{Cl})$ & & & \\
\hline \multicolumn{6}{|l|}{ Immigrant status } \\
\hline Long-term resident & 48921 & 1.00 (Reference) & Long-term resident & 1906 & 1.00 (Reference) \\
\hline Recent immigrant & 2262 & 0.60 (0.56 to 0.65$)$ & Recent Immigrant & 110 & $0.70(0.57$ to 0.85$)$ \\
\hline \multicolumn{6}{|c|}{ Immigrant status $\times$ time period $(\text { reference }=\text { period } 1)^{\star}$} \\
\hline Recent immigrant $\times$ time period & & 0.85 (0.81 to 0.89$)$ & Time period $†$ & & $0.98(0.96$ to 1.01$)$ \\
\hline Long-term resident $\times$ time period & & 0.91 (0.90 to 0.93$)$ & & & \\
\hline \multicolumn{6}{|l|}{ Sex } \\
\hline Female & 35332 & 1.00 (Reference) & Female & 503 & 1.00 (Reference) \\
\hline Male & 15851 & 0.43 (0.42 to 0.44$)$ & Male & 1513 & 2.87 (2.60 to 3.18$)$ \\
\hline \multicolumn{6}{|l|}{ Age } \\
\hline $10-14$ years & 12881 & 0.58 (0.55 to 0.60$)$ & $10-14$ years & 306 & $0.22(0.20$ to 0.26$)$ \\
\hline $15-19$ years & 25941 & 1.46 (1.41 to 1.51$)$ & 15-19years & 990 & 0.94 (0.85 to 1.03$)$ \\
\hline 20-24 years & 12361 & 1.00 (Reference) & 20-24 years & 720 & 1.00 (Reference) \\
\hline \multicolumn{6}{|l|}{ Neighbourhood income quintile } \\
\hline Quintile Missing & 518 & 2.42 (2.16 to 2.72$)$ & Quintile Missing & 88 & 8.32 (6.55 to 10.57$)$ \\
\hline Quintile 1 (lowest) & 12573 & $1.52(1.45$ to 1.60$)$ & Quintile 1 & 488 & 1.44 (1.26 to 1.65$)$ \\
\hline Quintile 2 & 10433 & 1.26 (1.20 to 1.32$)$ & Quintile 2 & 351 & $1.03(0.89$ to 1.19$)$ \\
\hline Quintile 3 & 9286 & 1.09 (1.04 to 1.14$)$ & Quintile 3 & 345 & 0.99 (0.85 to 1.14$)$ \\
\hline Quintile 4 & 9240 & 1.04 (0.99 to 1.09$)$ & Quintile 4 & 375 & $1.04(0.90$ to 1.20$)$ \\
\hline Quintile 5 & 9133 & 1.00 (Reference) & Quintile 5 & 369 & 1.00 (Reference) \\
\hline \multicolumn{6}{|l|}{ Community size } \\
\hline $1500000+$ & 13535 & 1.00 (Reference) & 1500000 & 587 & 1.00 (Reference) \\
\hline $500000-1499999$ & 7352 & 1.76 (1.66 to 1.88$)$ & $500000-1499999$ & 188 & 1.16 (0.99 to 1.37$)$ \\
\hline $100000-499999$ & 15874 & 1.79 (1.71 to 1.87$)$ & $100000-499999$ & 514 & $1.37(1.22$ to 1.55$)$ \\
\hline 10000-99999 & 6111 & 1.98 (1.88 to 2.08$)$ & 10000-99999 & 213 & $1.57(1.34$ to 1.85$)$ \\
\hline$<10000$ & 8311 & 1.83 (1.74 to 1.92$)$ & $<10000$ & 514 & $2.29(2.02$ to 2.60$)$ \\
\hline
\end{tabular}

${ }^{*}$ Relative rate of change in outcome rate per 3 -year time period.

†Interaction between immigrant status and time is not significant.

females, ${ }^{12}$ rural and urban youth, ${ }^{4}$ black and Caucasian children, ${ }^{3}$ and individuals by country of birth. ${ }^{20}$ Through these studies, variability in suicide risk within subpopulations has clearly been demonstrated, highlighting a number of contextual factors including immigration, that are important to explore to guide suicide prevention strategies. This study adds to a growing body of literature and the observed overall unchanged suicide trends are an important negative finding.

While fewer reports on self-harm trends in subpopulations exist, ${ }^{21}{ }^{22}$ these contextual analyses are equally important for identification of protective and precipitating contributors. They unearth opportunities for more targeted self-harm and suicide prevention strategies and supports. The observed decline in ED self-harm visits in our study may be related to widespread and concerted efforts to reduce mental health stigma, raise awareness including how and where to seek help, improved access to mental health services ${ }^{23}$ with strategies targeted particularly towards new immigrants. ${ }^{24}$ Conversely, the declining rates may, in part, be reflective of migratory shifts or to changes to social and religious supports - factors sometimes considered to be protective for mental health problems including in immigrants. ${ }^{25}{ }^{26}$ Declining trends in youth self-harm have also been reported across some ${ }^{1627}$ but not all 'Western' countries. ${ }^{22}$ While the mechanisms for decline remain speculative, the observation that rates are improving in both populations is promising. The observed decline in self-harm without a simultaneous decline in suicides in our population may reflect that a larger proportion of youth who self-harm are not presenting to the ED, or it may represent that suicide and self-harm are phenotypically different 
Table 3 Suicide by refugee status and region of birth (all periods pooled)

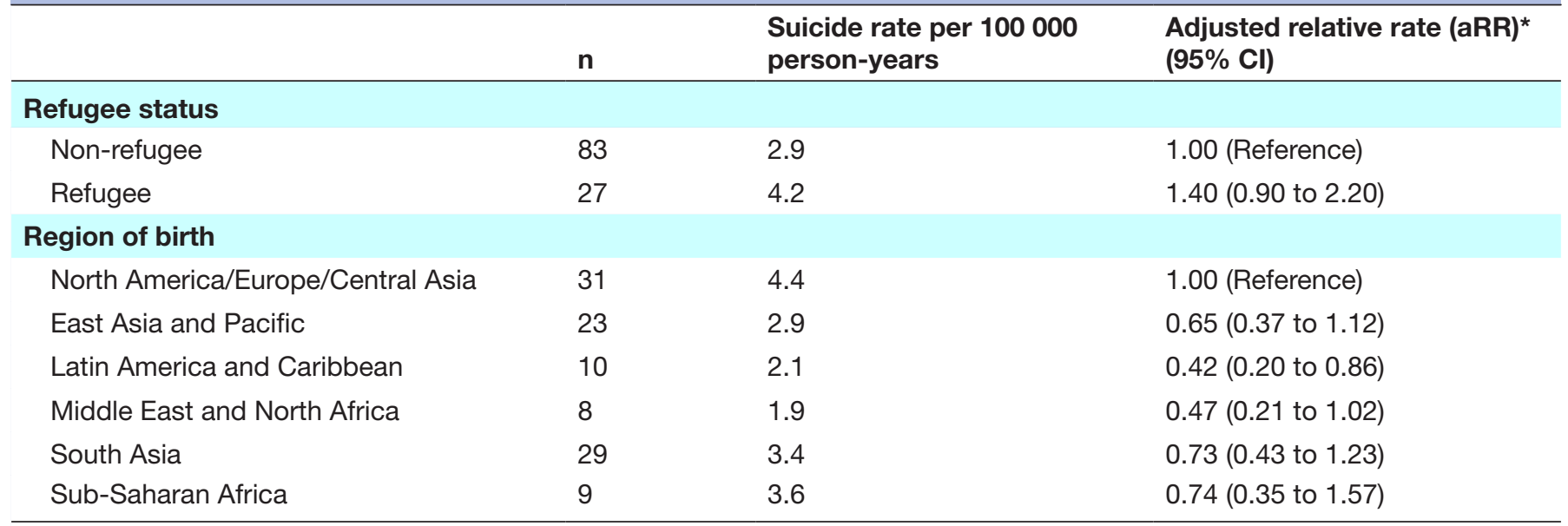

${ }^{*}$ Adjusted for age, sex, income quintile and community size.

with similar, but not identical, causal pathways and prevention mechanisms. The regional variation among immigrants within this study including the unchanged rates in self-harm over time in those from more 'Western' regions, signals an opportunity for exploring more targeted mental health supports.

Lower rates of suicide and ED self-harm in immigrant youth have previously been described, ${ }^{28}$ though not consistently, ${ }^{20}$ and support a healthy immigrant effect. ${ }^{30}$ Selection for individuals who may be more socially, emotionally and economically advantaged including refugees who successfully journey to Canada, may explain this finding. Furthermore, religious influences that may counter the risk of suicide ${ }^{26}$ and settling in communities with ethnically similar populations, especially greater metropolitan areas within Canada where many immigrants are situated, are proposed explanations for this observation and warrant further study ${ }^{2831}$ The different patterns of suicide and selfharm by sex and immigration status provide new insights. Firearm access, often cited as being associated with suicide
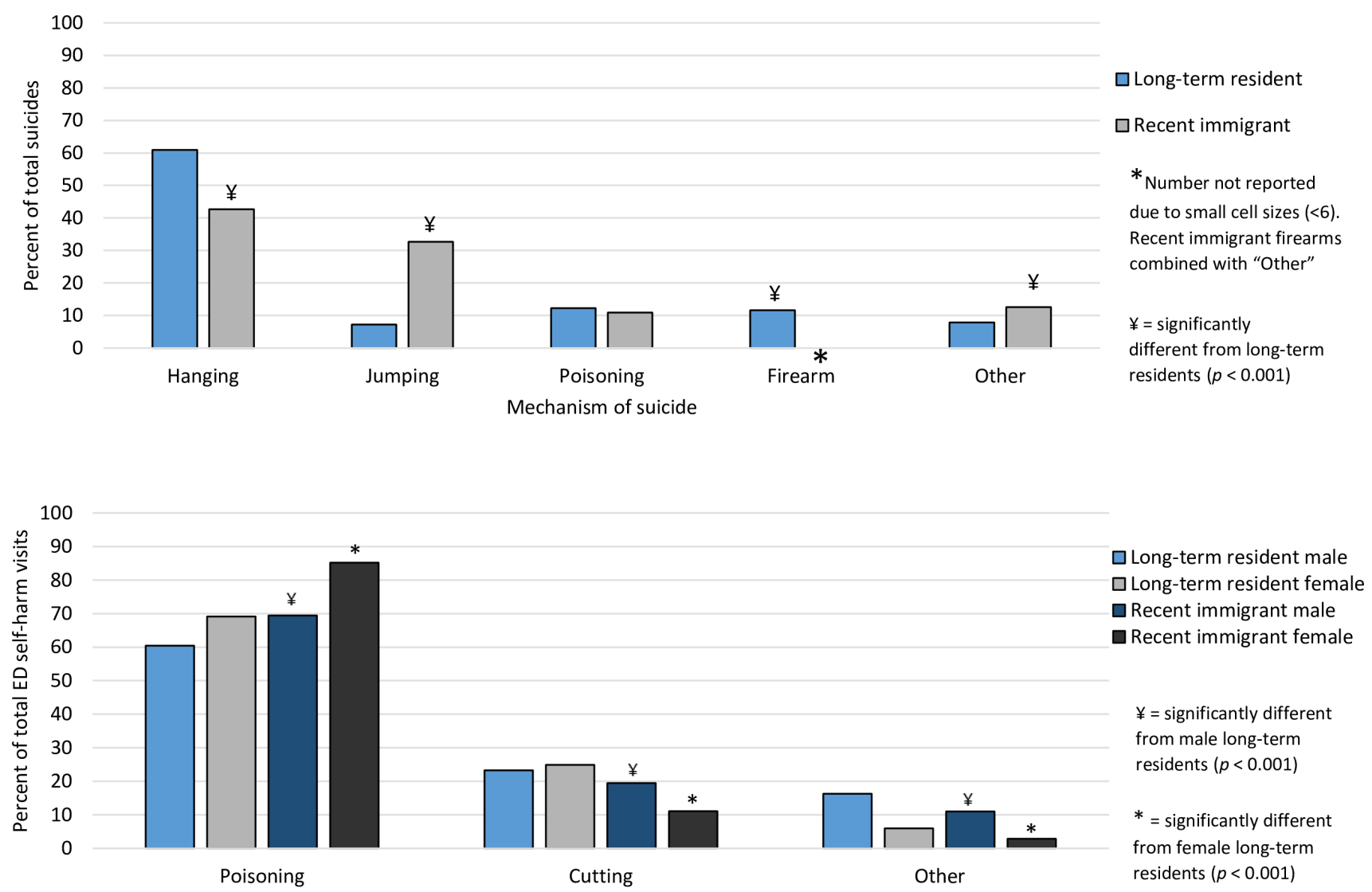

Mechanism of self-harm

Figure 2 Mechanism of suicide and self-harm by immigrant status. 


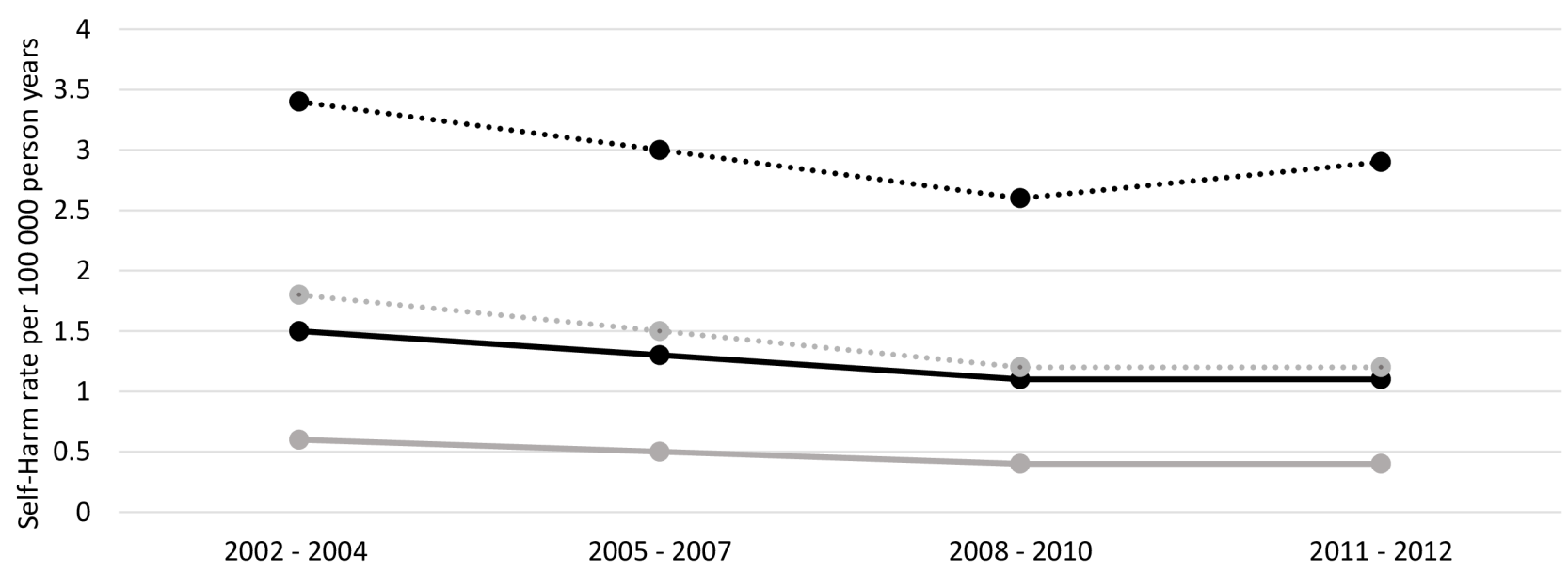

Cohort year

.••.• Female - long-term resident $\longrightarrow$-Male - long-term resident.$\odot$ Female - recent immigrant - - Male - recent immigrant

Figure 3 Trends in emergency department self-harm by immigrant status and sex.

Table 4 Emergency department visits for self-harm by refugee status and duration of residence and by region of birth

Model 1: refugee status and duration of
residence

Refugee status and duration of residence (Reference=non-refugee, $<5$ years)

$\begin{array}{ll}\text { Non-refugee, } 5-10 \text { years } & 1.02(0.85 \text { to } 1.22) \\ \text { Refugee, }<5 \text { years } & 1.72(1.39 \text { to } 2.12) \\ \text { Refugee, } 5-10 \text { years } & 1.21(0.88 \text { to } 1.64)\end{array}$

Refugee status and duration of residence by time (Reference=2002-2004 cohort)

\begin{tabular}{ll}
\hline Non-refugee, $<5$ years $\times$ time & $0.84(0.78$ to 0.91$)$ \\
\hline Non-refugee, $5-10$ years $\times$ time & $0.83(0.77$ to 0.91$)$ \\
\hline Refugee, $<5$ years $\times$ time & $0.83(0.75$ to 0.92$)$ \\
\hline Refugee, $5-10$ years $\times$ time & $0.97(0.84$ to 1.13$)$ \\
\hline Model 2: region of birth & \\
\hline Region of birth (Reference $=$ North America/Europe/Central Asia) \\
\hline East Asia and Pacific & $0.67(0.52$ to 0.87$)$ \\
\hline Latin America and the Caribbean & $1.12(0.86$ to 1.44$)$ \\
\hline Middle East and North Africa & $1.09(0.82$ to 1.45$)$ \\
\hline South Asia & $1.34(1.08$ to 1.67$)$ \\
\hline Sub-Saharan Africa & $0.96(0.68$ to 1.34$)$ \\
\hline Region of birth by time (Reference=2002-2004 cohort) \\
\hline North America/Europe/Central Asia $\times$ & $0.93(0.82$ to 1.06$)$ \\
\hline time & $0.84(0.75$ to 0.95$)$ \\
\hline East Asia and Pacific $\times$ time & $0.94(0.84$ to 1.04$)$ \\
\hline Latin America and Caribbean $\times$ time & $0.87(0.77$ to 0.99$)$ \\
\hline Middle East and North Africa $\times$ time & $0.79(0.73$ to 0.86$)$ \\
\hline South Asia $\times$ time & $0.81(0.67$ to 0.99$)$ \\
\hline Sub-Saharan Africa $\times$ time & \\
\hline
\end{tabular}

${ }^{\star}$ Adjusted for age, sex, income quintile, community size. by firearm, ${ }^{32}$ may be lower in recent immigrants. Selfharm by poisoning, which was strikingly higher in recent immigrant females, may represent attempts at more lethal suicide-related behaviour. In contrast, cutting, which represented almost a quarter of the mechanism of all ED selfharm visits in the remainder of the population, may signify a different phenotype of non-suicide self-injury.

\section{Strengths and limitations}

A strength of this study is that it is the first population-based study to evaluate trends over time in suicide and self-harm in immigrant youth. Detailed immigration data including immigration class and duration of residence were included for a large population with objective measures of mental health problems that were not based on self-report. This study focused on two very important times of transition and vulnerability-migration and adolescence-and therefore afford insights as to where to concentrate efforts to improve mental health. This study has several limitations including no measures of clinical comorbidities, no measures of language proficiency, inability to track immigrants who arrived in another province and then moved to Ontario, refugee claimants awaiting decision on their status and temporary and non-status immigrants. Exclusion of this latter, although small, potentially high risk group may have led to underestimation of our outcomes among immigrants. Fortunately, suicide in the recent immigrant population was rare, but the low number of events over the study years did not allow for trend studies in subpopulations of RI subgroups.

\section{Implications}

The trends in suicide and differential decline in selfharm rates by important subgroups should continue to be monitored with time. These represent opportunities from a population standpoint for public health policies and interventions to be evaluated. Current trends suggest 
opportunity for targeted self-harm reduction strategies for refugees, where the otherwise universal declines were not observed. Suicide trends imply shifts in migration have not affected rates of suicide in Canada and that despite expanded suicide prevention strategies, ${ }^{33}$ a concomitant decline in suicide rates within either population, has not occurred. Patterns of suicide and self-harm mechanisms may also have implications for availability and access to lethal means (ie, firearms) for at-risk populations which warrants further study. Linked administrative, health, vital statistics and immigration data can be used for ongoing monitoring of emerging trends to ensure early identification of subpopulations of immigrant youth in need of targeted, culturally and ethnically appropriate interventions.

\section{Author affiliations}

${ }^{1}$ Division of Pediatric Medicine, Hospital for Sick Children, Toronto, Canada

${ }^{2}$ Department of Pediatrics, University of Toronto, Toronto, Canada

${ }^{3}$ Institute for Clinical Evaluative Sciences, Toronto, Canada

${ }^{4}$ Child Health Evaluative Sciences, Sickkids Research Institute, Toronto, Canada

${ }^{5}$ Institute of Health Policy, Management and Evaluation, University of Toronto, Toronto, Canada

${ }^{6}$ Dalla Lana School of Public Health, University of Toronto, Toronto, Canada

${ }^{7}$ Centre for Urban Health Solutions, Li Ka Shing Knowledge Institute, St. Michael's Hospital, Toronto, Canada

${ }^{8}$ Manitoba Centre for Health Policy, Department of Community Health Services, Faculty of Health Sciences, University of Manitoba, Winnipeg, Manitoba, Canada ${ }^{9}$ Centre for Addiction and Mental Health, Toronto, Canada

Contributors NRS conceptualised and designed the study, interpreted the results, drafted the initial manuscript, revised the manuscript and approved the final manuscript as submitted. ML, TAS, MLU, PK and AG conceptualised and designed the study, interpreted the results, revised the manuscript and approved the final manuscript as submitted. HL conceptualised and designed the study, analysed the data, interpreted the results, revised the manuscript and approved the final manuscript as submitted. All authors approved the final manuscript as submitted and agree to be accountable for all aspects of the work.

Funding AG is funded through an Applied Chair in Reproductive and Child Health Services and Policy Research from the Canadian Institutes for Health Research (CIHR). MLU holds a CIHR New Investigator Award. Data cutting and analysis for this project were supported by a grant for the Mental Health and Addictions Evaluation Framework Team (MHASEF) at the Institute for Clinical Evaluative Sciences from the Ontario Ministry of Health and Long-Term Care (MOHLTC). This study was supported by the Institute for Clinical Evaluative Sciences (ICES), which is funded by an annual grant from the Ontario MOHLTC.

Disclaimer The opinions, results and conclusions reported in this paper are those of the authors and are independent from the funding sources. No endorsement by ICES or the Ontario MOHLTC is intended or should be inferred. Parts of this material are based on data and information compiled and provided by the Canadian Institute for Health Information (CIHI) and Immigration, Refugees and Citizenship Canada (IRCC). However, the analyses, conclusions, opinions and statements expressed herein are those of the authors and not necessarily those of $\mathrm{CIHI}$ or IRCC.

Competing interests None declared.

Patient consent Detail has been removed from this case description/these case descriptions to ensure anonymity. The editors and reviewers have seen the detailed information available and are satisfied that the information backs up the case the authors are making.

Ethics approval Sunnybrook Health Sciences Centre Resesarch Ethics Board.

Provenance and peer review Not commissioned; externally peer reviewed.

Data sharing statement The data setfrom this study is held securely in coded form at the Institute for ClinicalEvaluative Sciences (ICES). While data sharing agreements prohibit ICES frommaking the data set publicly available, access may be granted to those whomeet pre-specified criteria for confidential access, available at . The full data set creation plan is availablefrom the authors upon request.
Open Access This is an Open Access article distributed in accordance with the Creative Commons Attribution Non Commercial (CC BY-NC 4.0) license, which permits others to distribute, remix, adapt, build upon this work non-commercially, and license their derivative works on different terms, provided the original work is properly cited and the use is non-commercial. See: http://creativecommons.org/ licenses/by-nc/4.0/

(c) Article author(s) (or their employer(s) unless otherwise stated in the text of the article) 2017. All rights reserved. No commercial use is permitted unless otherwise expressly granted.

\section{REFERENCES}

1. World Health Organization. Suicide fact sheet. Secondary Suicide fact sheet. 2016 http://www.who.int/mediacentre/factsheets/fs398/ en/.

2. The Mental Health of Children and Youth in Ontario: A Baseline Scorecard. MHASEF Research Team. Toronto: Institute for Clinical Evaluative Sciences, 2015.

3. Bridge JA, Asti L, Horowitz LM, et al. Suicide Trends Among Elementary School-Aged Children in the United States From 1993 to 2012. JAMA Pediatr 2015;169:673-7.

4. Fontanella CA, Hiance-Steelesmith DL, Phillips GS, et al. Widening rural-urban disparities in youth suicides, United States, 1996-2010. JAMA Pediatr 2015;169:466-73.

5. Skegg K. Self-harm. Lancet 2005;366:1471-83.

6. World Health Organization. Suicide rates, age-standardized by country. 2015. http://apps.who.int/gho/data/view.main. MHSUICIDEASDRv?lang=en

7. Statistics Canada. Ten leading causes of death, by sex and geography, 2009 - Ontario. 2015. http://www.statcan.gc.ca/pub/84215-x/2012001/tbl/t019-eng.htm

8. Voracek M, Loibl LM. Consistency of immigrant and countryof-birth suicide rates: a meta-analysis. Acta Psychiatr Scand 2008;118:259-71.

9. Burvill PW. Migrant suicide rates in Australia and in country of birth Psychol Med 1998;28:201-8.

10. Statistics Canada. Immigration and Ethnocultural Diversity in Canada. 2013. http://www12.statcan.gc.ca/nhs-enm/2011/as-sa/99010-x/99-010-x2011001-eng.cfm

11. Citizenship and Immigration Canada. Facts and figures 2013. Immigration overview -permanent and temporary residents. 2013. http://www.cic.gc.ca/english/resources/statistics/facts2013/index. asp

12. Skinner R, McFaull S. Suicide among children and adolescents in Canada: trends and sex differences, 1980-2008. CMAJ 2012;184:1029-34

13. Rhodes AE, Bethell J, Carlisle C, et al. Time trends in suicide-related behaviours in girls and boys. Can J Psychiatry 2014;59:152-9.

14. Chiu M, Lebenbaum M, Lam K, et al. Describing the linkages of the immigration, refugees and citizenship Canada permanent resident data and vital statistics death registry to Ontario's administrative health database. BMC Med Inform Decis Mak 2016;16:135.

15. The World Bank Regions. 2015. http://www.worldbank.org/en/about/ annual-report/regions

16. Bergen $\mathrm{H}$, Hawton $\mathrm{K}$, Waters $\mathrm{K}$, et al. Epidemiology and trends in non-fatal self-harm in three centres in England: 2000-2007. Br J Psychiatry 2010;197:493-8.

17. Biddle L, Brock A, Brookes ST, et al. Suicide rates in young men in England and Wales in the 21st century: time trend study. BMJ 2008;336:539-42.

18. Fond G, Llorca PM, Boucekine M, et al. Disparities in suicide mortality trends between United States of America and 25 European countries: retrospective analysis of WHO mortality database. Sci Rep 2016;6:20256.

19. Statistics Canada. Suicide. 2016 http://www.statcan.gc.ca/eng/help/ $\mathrm{bb} / \mathrm{info} / \mathrm{suicide}$

20. Ide N, Kõlves K, Cassaniti M, et al. Suicide of first-generation immigrants in Australia, 1974-2006. Soc Psychiatry Psychiatr Epidemiol 2012;47:1917-27.

21. Hawton K, Haw C, Casey D, et al. Self-harm in Oxford, England: epidemiological and clinical trends, 1996-2010. Soc Psychiatry Psychiatr Epidemiol 2015;50:695-704.

22. Carr MJ, Ashcroft DM, Kontopantelis E, et al. The epidemiology of self-harm in a UK-wide primary care patient cohort, 2001-2013. BMC Psychiatry 2016;16:53.

23. Government of Ontario. Open minds, healthy minds: Ontario's Comprehensive MentalHealth and Addictions Strategy. 2011. http:// www.health.gov.on.ca/en/common/ministry/publications/reports/ mental_health2011/mentalhealth.aspx 
24. Hansson E, Tuck A, Lurie S, et al. Improving mental health services for immigrant, refugee, ethno-cultural and racialized groups: Issues and options for service improvement. Mental Health Commission of Canada, 2010.

25. Sisask $\mathrm{M}$, Varnik $\mathrm{A}$, Kolves $\mathrm{K}$, et al. Is religiosity a protective factor against attempted suicide: a cross-cultural case-control study. Arch Suicide Res 2010;14:44-55.

26. Bertolote J, Fleischmann A. A global perspective in the epidemiology of suicide. Suicidologi 2002;7:6-8.

27. Geulayov G, Kapur N, Turnbull P, et al. Epidemiology and trends in non-fatal self-harm in three centres in England, 2000-2012: findings from the Multicentre Study of Self-harm in England. BMJ Open 2016;6:e010538.

28. Malenfant EC. Suicide in Canada's immigrant population. Health Rep 2004;15:9-17.
29. Sorenson SB, Shen H. Youth suicide trends in California: an examination of immigrant and ethnic group risk. Suicide Life Threat Behav 1996;26:143-54.

30. Newbold KB. Health care use and the Canadian immigrant population. Int J Health Serv 2009;39:545-65.

31. El-Sayed AM, Tracy M, Scarborough P, et al. Suicide among ArabAmericans. PLoS One 2011;6:e14704.

32. Anglemyer A, Horvath T, Rutherford G. The accessibility of firearms and risk for suicide and homicide victimization among household members: a systematic review and meta-analysis. Ann Intern Med 2014;160:101-10.

33. Canadian Association for Suicide Prevention. Secondary Canadian Association for Suicide Prevention. http://suicideprevention.ca/. 